\title{
Erratum to: Editorial
}

\section{Hans L. Bodlaender ${ }^{2}$ • Mohammad Taghi Hajiaghayi ${ }^{1}$. Giuseppe F. Italiano ${ }^{3}$}

\section{Erratum to: Algorithmica DOI 10.1007/s00453-015-0074-y}

The publisher regrets that this Editorial was erroneously excluded from the preceding special issue: European Symposium on Algorithms, Algorithmica Volume 73, Issue 3. http://link.springer.com/journal/453/73/3/page/1.

The online version of the original article can be found under doi:10.1007/s00453-015-0074-y.

$\triangle$ Mohammad Taghi Hajiaghayi hajiagha@cs.umd.edu

1 University of Maryland, College Park, MD, USA

2 Utrecht University, Utrecht, Netherlands

3 Università di Roma "Tor Vergata", Roma, Italy 